\title{
A práxis da enfermagem de reabilitaçáo e os contributos da osteopatia
}

\author{
Rehabilitation nursing practice and the contribution of osteopathy \\ La práctica de la enfermería de rehabilitación y las contribuciones de la osteopatía
}

Artur José Caldas ${ }^{1}$

(D) https://orcid.org/0000-0002-9559-968X

Clara de Assis Coelho de Araújo ${ }^{2}$

(D) https://orcid.org/0000-0003-2295-0579

${ }^{1}$ Unidade Local de Saúde do Alto Minho Unidade de Cuidados na Comunidade de Melgaço, Melgaço, Portugal

${ }^{2}$ Unidade de Investigação em Ciências da Saúde: Enfermagem (UICISA: E). Escola Superior de Saúde do Instituto Politécnico de Viana do Castelo, Viana do Castelo, Portugal
Autor de correspondência: Artur José Caldas

Email: enfartur1974@gmail.com

\section{Resumo}

Enquadramento: A reabilitação, enquanto especialidade de enfermagem, abrange conhecimentos e procedimentos específicos que permitem auxiliar as pessoas a maximizar o seu potencial funcional e independência. $\mathrm{O}$ enfermeiro especialista em enfermagem de reabilitaçáo (EEER) tem a possibilidade de utilizar técnicas e tecnologias que não as comummente utilizadas no seu desempenho profissional, nomeadamente as da osteopatia, de modo a potenciar a efetividade dos cuidados.

Objetivo: Conhecer as vivências dos enfermeiros especialistas em enfermagem de reabilitação que utilizam técnicas osteopáticas na sua prática profissional.

Metodologia: Estudo exploratório descritivo, com recurso à entrevista semiestruturada a 8 enfermeiros, especialistas em enfermagem de reabilitação com formação e prática em osteopatia, recrutados através do método de amostra bola de neve. A técnica de tratamento de dados escolhida foi a análise de conteúdo.

Resultados: Os participantes consideram que superam os cuidados que prestam, aquando da utilização de técnicas ostopáticas.

Conclusáo: Considera-se que o recurso a técnicas osteopáticas, pode constituir um novo paradigma na práxis da enfermagem de reabilitação.

Palavras-chave: enfermagem em reabilitação; medicina osteopática

\section{Abstract}

Background: Rehabilitation nursing is a nursing specialty that comprises specific specific knowledge and procedures to help individuals maximize their functional potential and independence. The rehabilitation nurse is able to use techniques and technologies other than those that are commonly used in their professional practice, namely osteopathic techniques, in order to enhance the effectiveness of care.

Objective: To explore the experiences of rehabilitation nurses who use osteopathic techniques in their professional practice.

Methodology: Descriptive exploratory study using semi-structured interviews with 8 rehabilitation nurses with training and practice in osteopathy. They were recruited through the snowball sampling method. Data were processed using the content analysis technique.

Results: Participants believe that they provide more differentiated care when using osteopathic techniques. Conclusion: The use of osteopathic techniques may constitute a new paradigm in rehabilitation nursing practice.

Keywords: rehabilitation nursing; osteopathic medicine

\section{Resumen}

Marco contextual: La rehabilitación, como especialidad de enfermería, abarca conocimientos y procedimientos específicos que permiten ayudar a las personas a maximizar su potencial funcional y su independencia. El enfermero especialista en enfermería de rehabilitación (EEER) tiene la posibilidad de utilizar técnicas y tecnologías distintas de las utilizadas habitualmente en su desempeño profesional, en particular las de la osteopatía, a fin de aumentar la eficacia de la atención.

Objetivo: Conocer las experiencias de los enfermeros especialistas en enfermería de rehabilitación que utilizan técnicas osteopáticas en su práctica profesional.

Metodología: Estudio exploratorio descriptivo, en el que se recurrió a la entrevista semiestructurada a 8 enfermeros especialistas en enfermería de rehabilitación con formación y práctica en osteopatía, reclutados mediante el método de muestreo de bola de nieve. La técnica de tratamiento de datos elegida fue el análisis de contenido.

Resultados: Los participantes consideran que superan los cuidados que proporcionan cuando utilizan técnicas osteopáticas.

Conclusión: Se considera que el uso de técnicas osteopáticas puede constituir un nuevo paradigma en la práctica de la enfermería de rehabilitación.

Palabras clave: enfermería en rehabilitación; medicina osteopática 


\section{Introdução}

A reabilitação é o processo que visa ajudar uma pessoa a atingir o seu melhor potencial físico, psicológico, social, vocacional e educacional, compatível com o seu déficit fisiológico ou anatómico, limitaçóes ambientais, desejos e planos de vida tendo por base o conceito holístico, utilizando uma combinação de especialidades de vários profissionais de saúde (Santos, 2016).

De acordo com a avaliaçáo do estado de saúde do indivíduo, o enfermeiro especialista em enfermagem de reabilitação (EEER) elabora e negoceia o plano individual de intervenção onde deve incluir objetivos a curto e a longo prazo, orientando-os nas vertentes, física, social e comportamental, de acordo com as incapacidades e necessidades encontradas.

Questionada a Ordem dos Enfermeiros (OE) sobre a possibilidade do EEER utilizar na sua prática de cuidados, técnicas aprendidas num curso de osteopatia, responde com o seguinte parecer: "o enfermeiro especialista em enfermagem de reabilitação tem o direito de exercer livremente a profissão, designadamente no que se refere a intervenções com recurso a novas técnicas e tecnologias, nomeadamente as do âmbito da osteopatia" (OE, 2016, p. 3).

Do exposto, surge o interesse em conhecer a vivência dos EEER que utilizam técnicas osteopáticas na sua prática profissional, equacionando-se o seguinte objetivo geral: Conhecer as vivências dos EEER que utilizam técnicas osteopáticas na sua prática profissional.

Definiram-se os objetivos específicos para a operacionalização do objetivo geral: Analisar a experiência do EEER com utentes em que utiliza práticas osteopáticas; Identificar vantagens e constrangimentos percecionados em relação à utilização de técnicas osteopáticas na prática da enfermagem de reabilitação.

\section{Enquadramento}

O processo de reabilitaçáo, cujos objetivos estão centrados no desenvolvimento das capacidades potenciais da pessoa, conduz a uma maior independência em todas as dimensôes do ser humano (Santos, 2016).

"A reabilitação, enquanto especialidade multidisciplinar, compreende um corpo de conhecimentos e procedimentos específicos que permite ajudar as pessoas com doenças agudas, crónicas ou com as suas sequelas a maximizar o seu potencial funcional e independência” (Regulamento n. ${ }^{\circ} 392 / 2019$ de 3 de maio, p. 13565).

O enfermeiro especialista é o profissional de enfermagem que assume um "Conhecimento aprofundado num domínio específico de enfermagem, ... traduzidos num conjunto de competências especializadas relativas a um campo de intervenção (Regulamento n. ${ }^{\circ}$ 122/2011 de 18 de fevereiro, p. 8648) e "concebe, implementa e monitoriza planos de enfermagem de reabilitação diferenciados, baseados nos problemas reais e potenciais das pessoas" (Regulamento n.o 122/2011 de 18 de fevereiro, p. 13565). As técnicas utilizadas na osteopatia vêm acrescentar um considerável número de recursos, que os EEER podem utilizar na sua prática clínica, nomeadamente a mobilização e manipulação articular, técnicas para pontos-gatilho, técnicas viscerais e sacrocranianas, técnicas musculo energéticas, de impulso, miofasciais, entre outras.

Neste contexto, o processo de reabilitação exige a utilização de técnicas e ações interdisciplinares com o objetivo comum de melhor/reabilitar as funçóes comprometidas. Assiste-se, ao longo do tempo, a um aumento da procura de terapias complementares por parte das populaçôes. Os motivos que levam as pessoas a procurar e a utilizar estas terapias são idênticos aos motivos que as levam à procura dos serviços da medicina convencional, ou seja, a busca de cura ou saúde (Xavier, 2001).

É da responsabilidade do profissional de saúde aprofundar as suas competências para melhorar os resultados da sua intervenção no doente através da auto formação e reflexâo sobre a prática que "procura alcançar o pleno atendimento das necessidades e a máxima satisfação das expectativas dos clientes" (Lacerda, 2005, p. 20). Segundo Pestana (2016) a responsabilidade da melhoria contínua na prática profissional de enfermagem de reabilitação é do EEER, o que requer a aquisição contínua e atualizada de conhecimentos e competências que permitam fortalecer o julgamento crítico, a prática baseada na reflexão e a tomada de decisão para que seja capaz de cuidar da pessoa com necessidades especiais, ao longo do ciclo de vida e em todos os contextos da prática de cuidados, potenciando a funcionalidade e desenvolvendo as aptidóes da pessoa.

$\mathrm{Na}$ visão da osteopatia, qualquer alteração da mobilidade tecidual pode vir, a qualquer altura, comprometer a função de todo o organismo. Parte-se do princípio que qualquer mudança na mobilidade do aparelho locomotor pode dar lugar a um quadro patológico que pode ou não ser de cariz osteopático (Barreto, 2014) e difere da alopatia, principalmente no cuidado que presta à mecânica corporal e aos métodos de manipulaçáo utilizados no diagnóstico e tratamento (Ricard \& Vaca, 2017).

De acordo com a World Health Organization (2010) a osteopatia utiliza uma ampla variedade de técnicas manuais para melhorar a função prejudicada ou alterada por elementos relacionados com o sistema somático, esquelético, articular, miofascial, vascular, linfático e neural. Lam, Banihashem, Lam, Wan, e Chow (2019) levaram a cabo uma revisão sistemática da literatura com o objetivo de analisar e resumir sistematicamente a literatura de pesquisa primária referente à experiência e expectativas dos pacientes acerca do tratamento de manipulação osteopático, concluindo que a literatura primária relatou, principalmente, aspetos positivos sobre a experiência e expectativas dos pacientes acerca do tratamento de manipulação osteopático.

De acordo com o Regulamento n. ${ }^{\circ}$ 392/2019 de 3 de maio o avanço no conhecimento requer que o EEER participe em projetos de investigação que visem aumentar o conhecimento e o desenvolvimento de competências dentro da sua especialização, incluindo, na sua prática, os novos resultados da investigação. 
Segundo Ricard e Vaca (2017) as evidências sobre a abordagem osteopática são numerosas, sendo exemplo disso o International Journal of Osteopathic Medicine que publica exclusivamente investigaçóes nesta área.

\section{Questáo de investigaçáo}

Qual a vivência dos EEER que utilizam técnicas osteopáticas na sua prática profissional?

\section{Metodologia}

Dado o facto de se pretender conhecer a vivência dos EEER que utilizam técnicas osteopáticas na sua prática profissional, optou-se por um estudo de tipo exploratório-descritivo visto que se pretende nomear, categorizar, e descrever uma população ou conceptualizar uma situação (Fortin, 2009).

Sampieri, Collado, e Lucio (2013) referem que "é recomendável selecionar o enfoque qualitativo quando o tema de estudo foi pouco explorado, ou que não tenha sido realizada pesquisa sobre ele em algum grupo social específico" (Sampieri et al., 2013, p. 376) o que é o caso desta investigaçáo uma vez que em Portugal se desconhecem estudos sobre este tema.

Este estudo assenta no paradigma qualitativo, pois é neste que o investigador observa, descreve, interpreta com o objetivo de compreender o fenómeno tal como é vivido e relatado pelos participantes (Fortin, 2009).

A população-alvo, que segundo Fortin (2009) é constituída pelos elementos que satisfazem os critérios de seleção definidos é composta pelos enfermeiros com os seguintes critérios: Enfermeiros especialistas em enfermagem de reabilitação; Formação em osteopatia igual/superior a 2000h; Utilizar técnicas osteopáticas no seu exercício profissional.

Os participantes neste estudo, foram recrutados através do método de amostra bola de neve que segundo Bernard (2006) é um método de amostragem em rede utilizado para estudar populaçóes difíceis de encontrar, estudar ou quando não há exatidão sobre a sua quantidade.

Considera-se que a amostra está fechada quando existe saturação dos dados obtidos, indo ao encontro a Fontanella, Ricas e Turato (2008) quando referem que as informaçôes dadas pelos novos participantes pouco aditariam às informações já obtidas.

Para este estudo, optou-se pela entrevista porque é o método mais utilizado nos estudos exploratórios-descritivos sendo de utilização geral em quase todos os setores da população e inclui taxas mais altas de respostas que as conseguidas pelo questionário (Fortin, 2009).

$\mathrm{Na}$ construção da entrevista foram tidos em conta os objetivos da investigaçáo a fim de se conseguir conhecer as vivências dos EEER que utilizam técnicas osteopáticas na sua prática profissional. Após a realização das entrevistas procedeu-se à sua transcriçáo, a qual consti- tui uma fase importante de investigação, não devendo ser considerada como um mero detalhe técnico entre a realização da entrevista e a análise dos dados (Azevedo et al., 2017). Os dados foram recolhidos no período compreendido entre abril e setembro de 2018, após contacto prévio com os participantes e em local, data e hora por estes escolhida.

Visto que os dados do estudo em causa resultam do testemunho das perceçôes pessoais, obtidas através da aplicação de entrevistas semiestruturadas, considerou-se que a análise de conteúdo constitui o método mais adequado para o tratamento desses dados.

Após transcrição das entrevistas, procedeu-se à análise dos dados com o auxílio do computador e com recurso ao software NVivo ${ }^{\circledR}$ que como refere Sampieri et al. (2013, p. 477) "é um excelente programa de análise que é útil para criar bases de dados estruturadas hierarquicamente ... codifica unidades de conteúdo ... utilizando como base o esquema elaborado pelo pesquisador . . . um dos seus pontos fortes é criar matrizes".

As categorias de análise foram elaboradas com base no que os autores Sampieri et al. (2013) preconizam para esta atividade metodológica.

Foram tidos em conta os princípios éticos, ao ser pedida autorização para a recolha de dados, através de consentimento informado, após ter sido feita referência ao propósito do trabalho, assim como para gravação da entrevista, havendo compromisso na garantia do anonimato e confidencialidade de toda a informação adquirida. $O$ projeto que deu origem a este estudo de investigaçáo obteve o parecer favorável da Comissão de Ética da Unidade de Investigação em Ciências da Saúde: Enfermagem (UICISA: E) da Escola Superior de Enfermagem de Coimbra (Parecer No P524/10-2018).

\section{Resultados}

Participaram no estudo oito enfermeiros especialistas com experiência na utilizaçáo de técnicas osteopáticas. Seis participantes do sexo masculino dois do sexo feminino. Quatro participantes são detentores de licenciatura em enfermagem e quatro de mestrado, sendo que um elemento apresenta um mestrado fora do âmbito da enfermagem. A idade dos participantes está compreendida entre os 33 e os 60 anos, concentrando-se no intervalo dos 30 aos 40 anos onde encontramos seis participantes.

Relativo ao número de horas de formação em osteopatia, variam entre 2.000 a 3.600 horas. Todos os participantes possuem vasta experiência em enfermagem de reabilitação com recurso a técnicas osteopáticas.

Da consulta de frequência de palavras mais utilizadas pelos participantes nos seus discursos, verificamos que a palavra mais utilizada é técnicas que é usada 289 vezes, seguida da palavra reabilitação (197), osteopáticas (167) e enfermagem (114) como se pode verificar na nuvem de palavras que se apresenta na Figura 1. 


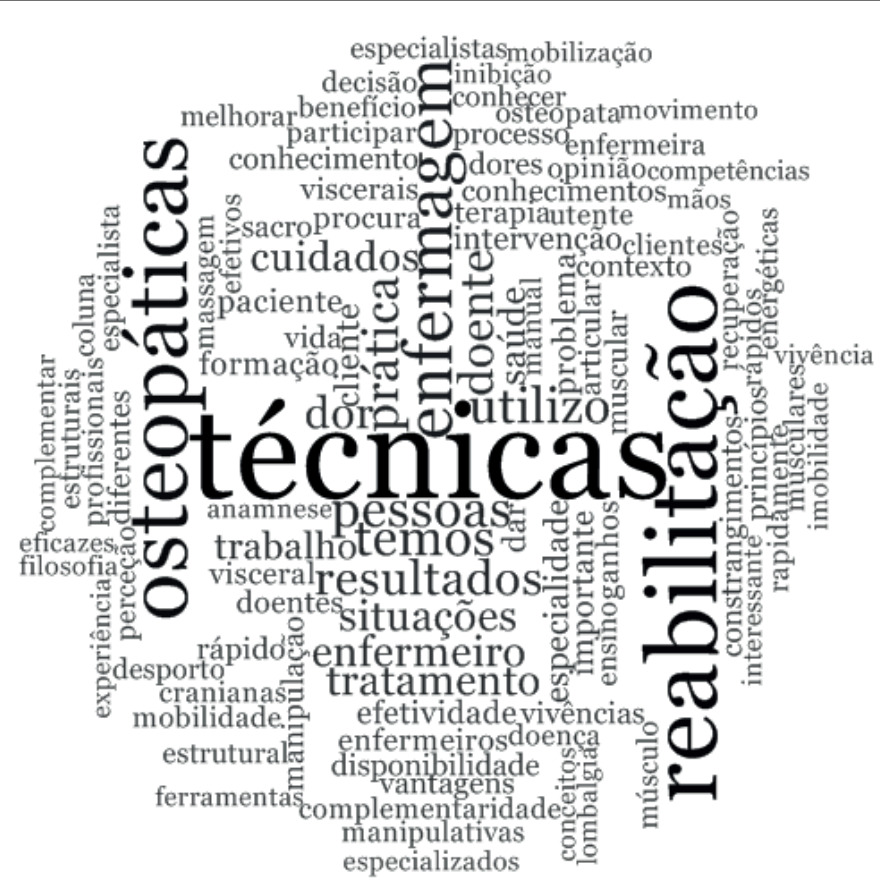

Figura 1. Consulta de frequência de palavras - nuvem de palavras.

Verifica-se ainda que os conteúdos das entrevistas apresentam uma correlaçáo muito forte $(0,9$ para mais ou para menos) e forte ( 0,7 a 0,9 positivo ou negativo), de acordo com o Pearson correlation coefficient como se pode visualizar na Figura 2.

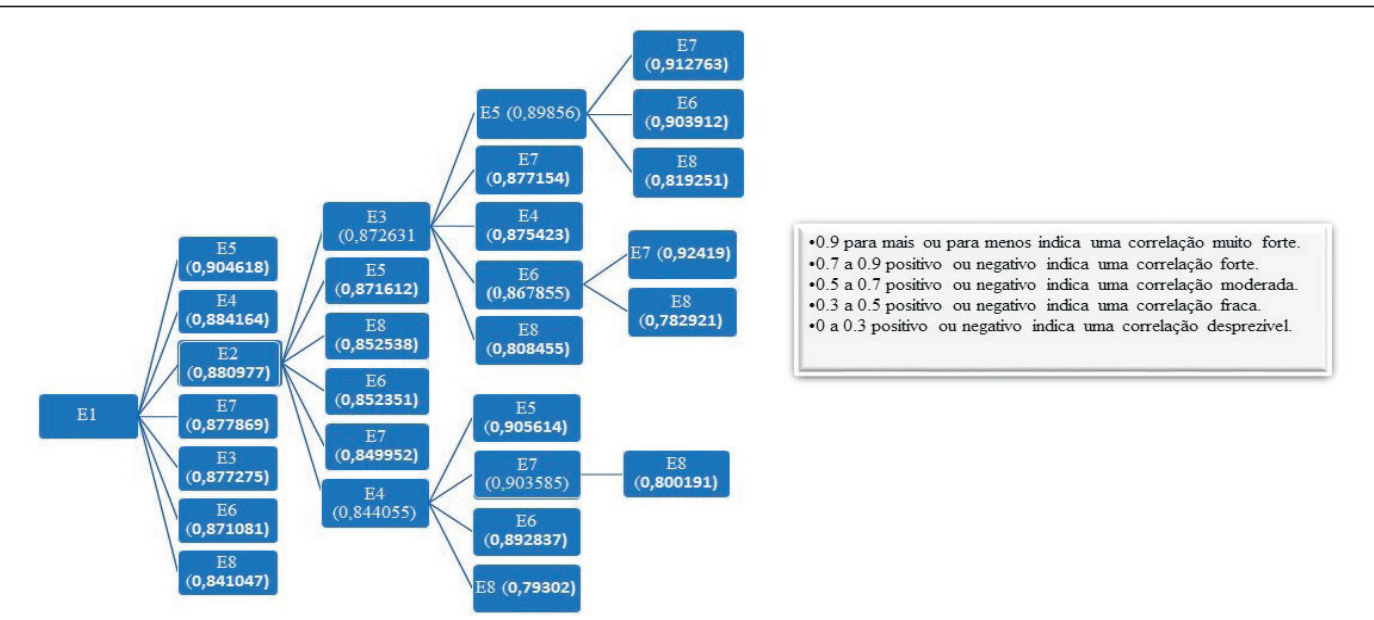

Figura 2. E = Entrevistado; Coeficiente de correlação das entrevistas (Pearson correlation coefficient).

A partir da análise dos textos transcritos das gravaçôes, foram contabilizadas as unidades de registo que se associam a cada uma das subcategorias e correspondente área temática. Os resultados identificados são apresentados na Tabela 1 .

Relativamente à questão de investigação, os participantes, contemplam as áreas temáticas Experiência na utilização de técnicas osteopáticas através de: Motivação para a mesma (15 unidades de registo; aquisiçâo de conhecimentos, influência de outros profissionais, influência familiar, novas abordagens, pela prática desportiva e resultados observados); Tipo de situaçôes clínicas ( 25 unidades de registo; alterações do equilíbrio, défice de aprendizagem, déficit de concentração, dislexia, do foro musculoesquelético, do foro neurológico, do foro visceral, dor, lesôes desportivas, síndrome de imobilidade e outras situaçóes); Tipo de práticas osteopáticas utilizadas (33 unidades de registo; massagem transversal profunda, técnicas linfáticas, técnicas de inibição, técnicas estruturais, técnicas miofasciais, técnicas musculoenergéticas, técnicas sacrocranianas, técnicas somatoemocionais, técnicas viscerais); Princípios subjacentes à sua utilização (22 unidades de registo; complementaridade de técnicas, consentimento do utente, perceção da eficácia, princípios éticos, avaliação do utente); Local de utilizaçáo (8 unidades de registo; consultório privado, cuidados de saúde primários, hospital privado) e 
Frequência de utilização (10 unidades de registo; sempre, muitas vezes, a maioria das vezes); Vantagens percecionadas na utilização de técnicas osteopáticas através da Complementaridade (7 unidades de registo); Efetividade dos cuidados (8 unidades de registo); Encurtamento do tempo de recuperação (8 unidades de registo); Ganhos económicos (5 unidades de registo); Nova filosofia de cuidar (5 unidades de registo); Satisfação do utente (1 unidade de registo); Rentabilização de recursos ( 2 unidades de registo) e Resultados no utente (7 unidades de registo) e Constrangimentos percecionados na utilização de técnicas osteopáticas onde é consensual a sua inexistência (8 unidades de registo).

Tabela 1

Áreas temáticas, categorias, subcategorias da análise dos conteúdos das narrativas dos participantes e frequência das unidades de registo

\begin{tabular}{|c|c|c|c|}
\hline Área temática & Categorias & Subcategorias & N.o \\
\hline \multirow{35}{*}{$\begin{array}{l}\text { Experiência do enfermeiro especialis- } \\
\text { ta em enfermagem de reabilitação na } \\
\text { utilização de técnicas osteopáticas }\end{array}$} & \multirow{6}{*}{ Motivação para a mesma } & Aquisição de conhecimentos & 5 \\
\hline & & Influência de outros profissionais & 2 \\
\hline & & Influência familiar & 1 \\
\hline & & Novas abordagens & 1 \\
\hline & & Pela prática desportiva & 4 \\
\hline & & Resultados observados & 2 \\
\hline & \multirow{9}{*}{ Tipo de situaçôes clínicas } & Alterações do equilíbrio & 2 \\
\hline & & Dificuldades de Aprendizagem & 1 \\
\hline & & Do foro musculoesquelético & 7 \\
\hline & & Do foro neurológico & 1 \\
\hline & & Do foro visceral & 2 \\
\hline & & Dor & 5 \\
\hline & & Lesões desportivas & 2 \\
\hline & & Síndrome de imobilidade & 2 \\
\hline & & Outras situaçōes & 3 \\
\hline & \multirow{9}{*}{ Tipo de Práticas osteopáticas utilizadas } & Massagem transversal profunda & 1 \\
\hline & & Técnicas Linfáticas & 1 \\
\hline & & Técnicas de inibição & 2 \\
\hline & & Técnicas estruturais & 4 \\
\hline & & Técnicas miofasciais & 5 \\
\hline & & Técnicas musculoenergéticas & 6 \\
\hline & & Técnicas sacrocranianas & 8 \\
\hline & & Técnicas somatoemocionais & 1 \\
\hline & & Técnicas viscerais & 5 \\
\hline & \multirow{5}{*}{ Princípios subjacentes à sua utilização } & Complementaridade de técnicas & 5 \\
\hline & & Consentimento do utente & 5 \\
\hline & & Perceção da eficácia & 5 \\
\hline & & Princípios éticos & 1 \\
\hline & & Avaliação do utente & 6 \\
\hline & \multirow{3}{*}{ Local de utilização } & Consultório Privado & 6 \\
\hline & & Cuidados de saúde primários & 1 \\
\hline & & Hospital privado & 1 \\
\hline & \multirow{3}{*}{ Frequência de utilização } & Sempre & 2 \\
\hline & & Muitas vezes & 4 \\
\hline & & A maioria das vezes & 4 \\
\hline \multirow{8}{*}{ Vantagens percecionadas } & Complementaridade & & 7 \\
\hline & Efetividade dos cuidados & & 8 \\
\hline & Encurtamento do tempo de recuperação & & 8 \\
\hline & Ganhos económicos & & 5 \\
\hline & Nova filosofia de cuidar & & 5 \\
\hline & Satisfação do utente & & 1 \\
\hline & Rentabilização de recursos & & 2 \\
\hline & Resultados no utente & & 8 \\
\hline Constrangimentos percecionados & Sem Constrangimentos & & 8 \\
\hline TOTAL & & & 165 \\
\hline
\end{tabular}




\section{Discussão}

Os resultados da análise do conteúdo das entrevistas, permitiram enquadrar os participantes no que se refere à sua experiência na utilização de técnicas osteopáticas, nomeadamente: Motivação; tipo de situaçóes, tipo de práticas utilizadas, princípios subjacentes à sua utilização, local onde utiliza e frequência de utilização.

Ao nível da motivação foi possível verificar que $50 \%$ dos participantes referem a aquisição de conhecimentos como fator determinante no seu desenvolvimento profissional com o objetivo de se tornarem cada vez mais habilitados. No que se refere à influência de outros profissionais, um informante aponta experiências formativas anteriores e outro a experiência com a observaçáo de outro profissional da área da terapia manual que despertou o seu interesse para a formação e posteriormente para a utilização de técnicas osteopáticas.

$\mathrm{Na}$ atualidade verifica-se um crescente interesse pelas técnicas osteopáticas por parte de EEER que praticam uma modalidade desportiva, porque observaram resultados que apareciam de forma positiva, nomeadamente na recuperação rápida de atletas, com recurso a técnicas de reabilitação e apoio de práticas osteopáticas, facto referido por metade dos participantes.

No que se refere ao tipo de situaçóes em que os EEER utilizam técnicas osteopáticas, estas são muito variadas e mostram o extenso leque de situaçóes em que a nossa atuação pode ser mais efetiva. As alteraçóes do equilíbrio são referidas por dois participantes. Na verdade, há uma relação entre a osteopatia e o tratamento de alteraçóes do equilíbrio, mas seja por questóes visuais, psiquiátricas ou até de mobilidade, a osteopatia mostra-se acessível e eficaz para reverter o quadro da popular tontura (Lima, 2018). Outras situaçôes clínicas apontadas nos discursos de sete participantes estão relacionadas com as patologias do foro musculosquelético indo de encontro ao referido pela Direção-Geral da Saúde (DGS, 2008) quando diz que o tratamento osteopático promove a função otimizada do sistema neuro músculo esquelético que influencia todos os sistemas do corpo, incluindo as vísceras num contexto de abordagem holística, através dum modelo de saúde e doença biomédicopsicosocial.

De todas as situações musculosqueléticas apresentadas pelos participantes, destacam-se as patologias da coluna, nomeadamente as cervicalgias referida por três participantes, a lombalgia referida por quatro participantes e todas as situações que envolvam dor.

A terapia manual é frequentemente utilizada com a finalidade de melhorar a amplitude de movimento, aliviar a dor, e restaurar a função. Diferentes técnicas são utilizadas visando o aumento da amplitude de movimento articular $(\mathrm{ADM})$ e a melhoria da funcionalidade das regióes lombar e cervical, como o emprego de técnicas de mobilização ou de manipulaçáo de pequena amplitude com impulso de alta velocidade.

Em relação ao tipo de práticas osteopáticas utilizadas pelos nossos participantes, são referidas várias, com destaque para as técnicas sacrocranianas que são referidas por todos os participantes, miofasciais, referida por cinco participan- tes, musculoenergéticas apontadas por seis participantes, estruturais, utilizadas por quatro participantes e viscerais, apontadas por cinco informantes.

Procurou-se analisar os princípios subjacentes à utilização de práticas osteopáticas por parte dos nossos participantes. Da análise efetuada, verifica-se que estes são variados, nomeadamente: complementaridade de técnicas referida por cinco participantes, consentimento do utente e a perceção da eficácia narrada por cinco participantes, os princípios éticos, relatado por um participante e a avaliação do utente mencionada por seis participantes.

Pode-se verificar, da análise das informaçōes, a constante preocupação da perceção da eficácia das técnicas utilizadas na observação dos resultados esperados o que deve permitir a melhoria contínua das práticas.

Vive-se um tempo de transição em que somos interpelados a complementar a nossa atuaçáo, enquanto enfermeiros especialistas em enfermagem de reabilitação, com outras técnicas e tecnologias que não as comummente utilizadas. Como em todo o cuidado de enfermagem, requer o consentimento do utente, sendo este outro princípio apontado pela maioria dos participantes (cinco) reconhecendo assim o valor da autonomia do utente.

Em toda a nossa prática temos como premissa a negociação do plano de cuidados elaborado de acordo com o diagnóstico formulado. Este aspeto está bem patente nos discursos dos nossos participantes quando se referem como princípio subjacente à utilização de práticas osteopáticas, o consentimento do utente, o que vai ao encontro ao preconizado pela Direção-Geral da Saúde quando diz que os profissionais de saúde mantêm a privacidade dos seus utentes; doentes ou utentes na relação terapêutica. Respeitam as ideias, os desejos e os direitos dos pacientes, doentes ou utentes ou clientes, e obtêm o seu consentimento, interagem com e tratam os pacientes com sensatez, ponderação, com dignidade, respeito, gentilmente, e mantêm a sua confidencialidade. (DGS, 2008, p. 1). Apenas um participante faz referência ao princípio ético da não maleficência, mas é sabido que toda a prática de enfermagem é alicerçada nos princípios éticos e deontológicos devidamente publicados no regulamento do exercício profissional do enfermeiro. A enfermagem fundamenta a sua prática num agir que tem em vista o melhor bem para a pessoa cuidada, respeitando os direitos humanos nas relaçóes interpessoais que estabelece.

No exercício das suas funções, os enfermeiros deverão adotar uma conduta responsável e ética e atuar no respeito pelos direitos e interesses legalmente protegidos dos cidadãos (OE, 2016).

A avaliação do utente, é outro aspeto referido como princípio subjacente para a utilização de técnicas osteopáticas e está patente nos discursos de seis participantes e permite ao enfermeiro realizar o diagnóstico, planificar as intervençôes de enfermagem, acompanhar e avaliar a evolução do utente.

Dos resultados obtidos foi possível observar que o local onde os participantes utilizam técnicas osteopáticas variam. Seis participantes, utilizam-nas em consultório privado, próprio ou partilhado. Somente um participante utiliza técnicas osteopáticas em contexto de cuidados saúde 
primários (Equipa de Cuidados Continuados Integrados) e outro em contexto hospitalar privado. O EEER tem o direito de exercer livremente a profissão (OE, 2016) na qualidade de independente, em regime de contrato de trabalho, ou como funcionário de um serviço público, pode praticar a profissáo isoladamente, como colaborador de um ou de vários colegas, ou em associação.

É possível reconhecer, pela análise do conteúdo das oito entrevistas, que todos os participantes referem a complementaridade, a efetividade de cuidados, o encurtamento do tempo de recuperaçáo e os resultados observados nos utentes como vantagens percecionadas na utilização de técnicas osteopáticas.

Os enfermeiros têm uma atuação de complementaridade funcional relativamente aos demais profissionais de saúde, mas dotada de idêntico nível de dignidade e autonomia de exercício profissional (Comissão de Especialidade de Enfermagem de Reabilitação, 2010).

Verifica-se que todos os participantes fazem menção à efetividade, como grande vantagem da utilização de técnicas osteopáticas, razão pela qual é referida por todos os participantes. Pode-se constatar que a explicação estará sempre nos resultados que se obtêm, ou seja, no impacto das medidas no estado de saúde das populaçóes em geral e de cada um dos cidadãos em particular, isto é, na efetividade (Amaral, 2014).

A enfermagem é incitada a demonstrar a efetividade dos seus cuidados e da qualidade dos mesmos pelo que é impreterível demonstrar o valor das suas intervençôes. No discurso de cinco participantes encontramos referência a ganhos económicos, enquanto vantagem percecionada, decorrente da utilização de técnicas osteopáticas, no seu desempenho de EEER.

A excelência da enfermagem de reabilitaçáo pode trazer ganhos em saúde que se traduzem quer pela redução de episódios de doença, incapacidade temporária ou permanente, quer pelo aumento da funcionalidade física e psicossocial, contribuindo, deste modo, para uma melhoria da qualidade de vida (DGS, 2013).

A utilização de técnicas osteopáticas pelos EEER, participantes neste estudo, constitui uma nova filosofia de cuidar. Quatro enfermeiros referem que estas técnicas trazem uma nova maneira de ver o cuidar em reabilitação, através do processo de cuidados que é semelhante, trazendo uma outra visáo da saúde e da doença.

Segundo Barreto (2014), a osteopatia é um sistema de avaliação e tratamento, com filosofia e metodologia próprias, com o objetivo de restabelecer a função das estruturas e sistemas corporais. Outro aspeto referido por dois dos participantes é a rentabilização de recursos que se observa com a utilização de técnicas osteopáticas. Se o encurtamento do tempo de recuperação, os resultados observados nos utentes e a efetividade de cuidados, são realidades percecionadas por todos os participantes, já referido anteriormente, rápido se compreende que podemos rentabilizar recursos, quer humanos, materiais e consequentemente económicos.

Os EEER, que utilizam técnicas osteopáticas, sentem-se capazes, seguros e sem qualquer pressão no exercício das suas funçōes especializadas, o que se verifica no discurso de todos os participantes, razão pela qual não mencionam percecionar constrangimentos na utilização de técnicas osteopáticas pois têm a preocupação constante de adquirirem formação por forma a assegurar o cumprimento dos requisitos habilitacionais e das condiçóes essenciais ao exercício da profissão de enfermagem.

As limitaçōes deste estudo incidiram sobre a dificuldade em encontrar literatura relativa a este tema dada a sua atualidade no que concerne ao recurso a técnicas osteopáticas na práxis de enfermagem de reabilitação.

Embora a amostra possa ser considerada uma limitação do estudo, considera-se ser diversificada pois dá resposta ao objetivo de conhecer a vivência dos enfermeiros especialistas em enfermagem de reabilitação sobre a sua experiência, vantagens e constrangimentos na utilização de técnicas osteopáticas e a sua efetividade no cuidar em enfermagem de reabilitação.

O facto de se desconhecer evidência sobre a contribuição das práticas osteopáticas na intervenção em enfermagem de reabilitaçáo, conduz-nos a considerar a oportunidade e pertinência para a realização deste estudo.

\section{Conclusão}

Com a realização deste estudo, fica-se com a convicção da sua mais valia para a enfermagem de reabilitação através do conhecimento das vivências dos EEER que utilizam práticas específicas de outra disciplina no seu desempenho profissional especializado em reabilitação.

O EEER, reconhece a importância de alargar o seu horizonte e investir na sua formação contínua para que possa fazer face aos avanços no conhecimento do processo saúde-doença tendo em vista a satisfação e a excelência do cuidar, num tempo em que a sociedade se mostra cada vez mais exigente.

Considera-se que as conclusóes retiradas deste estudo se revelam pertinentes no processo de conhecimento deste fenómeno no desempenho profissional destes enfermeiros, alargando horizontes na sua área de atuação tornando-se adequada a realizaçáo de futuros estudos, no sentido de conhecer mais profundamente a influência das técnicas osteopáticas na práxis da enfermagem de reabilitação.

\section{Contribuiçáo de autor}

Conceptualização: Caldas, A. J.

Tratamento de dados: Caldas, A. J.; Araújo, C. A.

Metodologia: Caldas, A. J.; Araújo, C. A.; Supervisão, Araújo, C. A.

Redação - preparação do rascunho original: Caldas, A. J. Redação - revisão e edição: Caldas, A. J.; Araújo, C. A.

\section{Referências bibliográficas}

Amaral, A. (2014). Um modelo de efetividade de cuidados em enfermagem. Revista Investigação em Enfermagem, 8(1), 20-34.

Azevedo, V., Carvalho, M., Costa, F. F., Mesquita, S., Soares, J., Teixeira, F., \& Maia, A. (2017). Transcrever entrevistas: Questóes conceptuais, orientaçôes práticas e desafios. Revista de Enfermagem 
Referência, 4(14), 159-168. doi:10.12707/RIV17018

Barreto, N. (2014). Componentes de formação no plano de estudos: A componente prática num curso profissional de Osteopatia (Dissertação de mestrado). Universidade Aberta, Lisboa, Portugal.

Bernard, R. (2006). Research methods in anthropology: Qualitative and quantitative approaches. Lanham, MD: AltaMira Press.

Comissão de Especialidade de Enfermagem de Reabilitação. (2010). Enfermagem de Reabilitação e cuidados continuados: Consolidação de premissas antigas ou um novo desafio? Ordem dos Enfermeiros, 33, 22-27.

Direção Geral da Saúde. (2008). Osteopatia resumo da caracterização da terapêutica e do perfil do profissional. Recuperado de https:// www.dgs.pt/ficheiros-de-upload-1/tnc-osteopatia-completo.aspx.

Direção-Geral da Saúde. (2013). Plano Nacional de Saúde 2012-2016. Recuperado de http://pns.dgs.pt/files/2013/05/PNS2012_2016_ versaoresumo_maio20133.pdf.

Fontanella, B., Ricas, J., \& Turato, E. (2008). Amostragem por saturação em pesquisas qualitativas em saúde: Contribuiçóes teóricas. Cadernos de Saúde Pública, 24(1), 17-27. doi:10.1590/ SO102-311X2008000100003

Fortin, M. (2009). O processo de investigação: Da conceção à investigação. Loures, Portugal: Lusociência.

Lacerda, F. (2005). Gestäo da qualidade: Fundamentos da excelência. Brasília, Brasil: Sebrae.

Lam, M., Banihashem, M., Lam, H., Wan, A., \& Chow, E. (2019). Patient experience, satisfaction, perception and expectation of osteopathic manipulative treatment: A systematic review. International Journal of Osteopathic Medicine, 32(19), 28-43. Recuperado de https://www.journalofosteopathicmedicine.com/article/ S1746-0689(18)30131-7/fulltext

Lima, W. (2018). A osteopatia e as vertigens: Entenda a relação. Re- cuperado de http://osteopatiasp.com.br/osteopatia-vertigens.

Ordem dos Enfermeiros. (2016). Parecer n.o 06/2016. Utilização da osteopatia nos cuidados prestados por enfermeiro especialista em Enfermagem de Reabilitação. Recuperado de http//www.ordemenfermeiros.pt/documentos/Documents/Parecer_06_2016_MCEER_UtilizacaoOsteopatiaCuidadosPrest.pdf.

Pestana, H. (2016). Cuidados de enfermagem de reabilitaçáo: Enquadramento. In C. Vieira \& L. Sousa (Eds.), Cuidados de enfermagem de reabilitação à pessoa ao longo da vida (pp. 47-55). Loures, Portugal: Lusodidacta.

Regulamento n. ${ }^{\circ}$ 122/2011 de 18 de fevereiro. Diário da República $n^{o}$ 35/08 II Série, Parte E. Ordem dos Enfermeiros. Lisboa, Portugal

Regulamento n. ${ }^{\circ}$ 392/2019 de 3 de maio. Diário da República $n^{\circ}$ 85/2019 II Série. Ordem dos Enfermeiros. Lisboa, Portugal.

Ricard, F., \& Vaca, A. (2017). Osteopatía basada en la evidencia: Evidencia cientifica y bases de la osteopatía. Madrid, España: Medos Edición.

Sampieri, R. H., Collado, C.F., \& Lucio, P. B. (2013) Metodologia de pesquisa (5a ed.). São Paulo, Brasil: McGraw Hill.

Santos, L. (2016). O processo de reabilitação. In C. Vieira \& L. Sousa (Eds.), Cuidados de enfermagem de reabilitação à pessoa ao longo da vida (pp. 15-23). Loures, Portugal: Lusodidacta.

World Health Organization. (2010). Benchmarks for training in traditional / complementary and alternative medicine - Benchmarks for Training in Osteopathy. Recuperado de https://www. who.int/medicines/areas/traditional/BenchmarksforTraininginOsteopathy.pdf

Xavier, B. (2001). Terapias alternativas e sociedade moderna: Popularidade e consumo de medicinas não convencionais. Revista de Enfermagem Referência (6), 23-28. 